
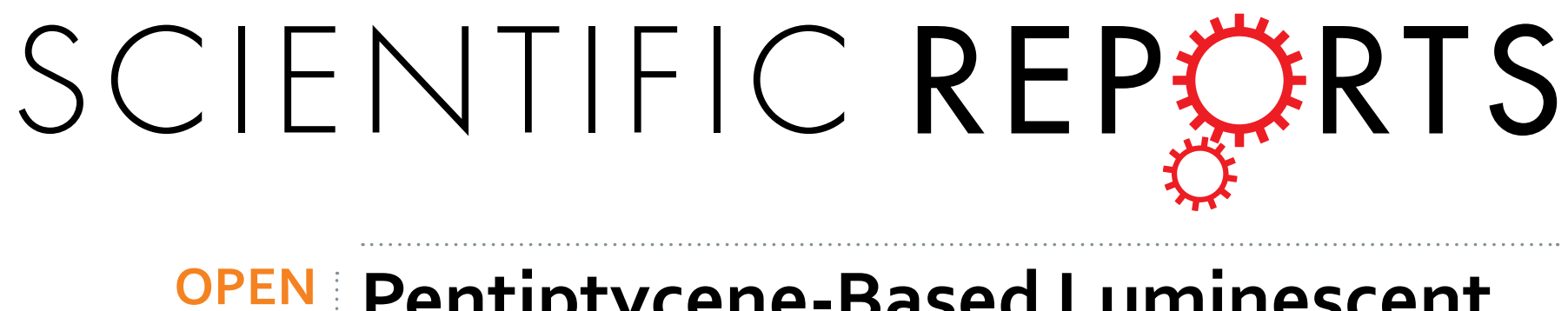

\title{
Pentiptycene-Based Luminescent Cu (II) MOF Exhibiting Selective Gas Adsorption and Unprecedentedly \\ High-Sensitivity Detection of Nitroaromatic Compounds (NACs)
}

Received: 27 October 2015

Accepted: 11 January 2016

Published: 09 February 2016

\author{
Minghui Zhang ${ }^{*}$, Liangliang Zhang*, Zhenyu Xiao, Qinhui Zhang, Rongming Wang, \\ Fangna Dai \& Daofeng Sun
}

The assembly of a fluorescent pentiptycene-based ligand with copper ion resulted in the formation of a 3D porous metal-organic framework (UPC-21) based on well-known paddlewheel SBUs. UPC-21 exhibits selective adsorption of $\mathrm{CO}_{2}$ over $\mathrm{CH}_{4}$ and $\mathrm{N}_{2}$ at $273 \mathrm{~K}$ and $295 \mathrm{~K}, \mathrm{C}_{2} \mathrm{H}_{2}$ over $\mathrm{CH}_{4}$ at $273 \mathrm{~K}$. The most significant performance of UPC-21 is its highly efficient detection of NACs such as 4-NP, 1,4DNB, NB, and 1,3-DNB with the calculated quenching constants, $K_{\text {sv }}$, being $3.097 \times 10^{6}, 1.406 \times 10^{6}$, $4.420 \times 10^{5}$, and $1.498 \times 10^{5} \mathrm{M}^{-1}$ for 4-NP, 1,4-DNB, NB, 1,3-DNB, respectively, which keeps a record on the fluorescence detection of NACs. This is the first porous $\mathrm{Cu}$ (II) MOF that exhibits fluorescent detection of NACs with high sensitivities.

The development of metal-organic frameworks (MOFs) has provided an excellent platform for rational design and synthesis of functional materials with desired properties ${ }^{1-5}$. Through careful design or select of organic ligand, functional MOFs with gas storage/separation, catalysis, and luminescent sensors were successfully constructed and reported in the past decades ${ }^{6-13}$. In particular, construction of MOF-based luminescent sensor has been received much attention of chemists due to its potential application in detection of nitroaromatic compounds (NACs). Nitroaromatics (NACs), which are composed of a benzene ring functionalized with several nitro-groups, have become serious pollution sources due to their explosivity and high toxicity. Beside, the structural tailorability and chemical versatility provide a significant level of tenability to detection of NACs with MOFs ${ }^{14}$. In general, it is highly dependent on the organic ligand or metal ion/cluster for the fluorescent behaviour of a MOF material. Hence, a large number of luminescent MOFs based on organic ligands with chromophores or metal ions such as $\mathrm{Cd}^{2+}, \mathrm{Zn}^{2+}, \mathrm{Ln}^{3+}$, or the combination of these two parts have been widely synthesized, and their application in fluorescent detection of NACs has been studied in recent years ${ }^{15-21}$. Surprisingly, study of fluorescent Cu(II) MOF on the application of sensing NACs remains unexplored, although porous Cu(II) MOFs with high gas uptake can be easily constructed by the assembly of carboxylate ligands with $\mathrm{Cu}$ (II) ions $\mathrm{s}^{22-25}$. Furthermore, the detection sensitivity is somewhat low for the reported luminescent MOFs on the detection of NACs. Thus, construction of luminescent MOFs with high-sensitivity detection of NACs is still a great challenge to chemists.

On the other hand, organic ligands used for the construction of functional MOFs are limited in phenyl- or anthracene-based carboxylate or $\mathrm{N}$-donor ligands ${ }^{26-31}$. However, the application of iptycene-based organic ligands in the assembly of porous MOFs is quite rare ${ }^{32}$. Actually, iptycene-based conjugated polymers were widely synthesized and studied, which exhibits excellent fluorescence sensing applications ${ }^{33}$. Moreover, the rigid iptycene groups can significantly prevent aggregation of the polymers to generate excellent properties ${ }^{34}$. Similar results should be achieved if the iptycene-based ligands are used to construct functional MOFs. Very recently, MOFs constructed from triptycene- and pentiptycene-based carboxylate ligands were reported by MacLachlan and

State Key Laboratory of Heavy Oil Processing, China University of Petroleum (East China), College of Science, China University of Petroleum (East China), Qingdao Shandong 266580, People's Republic of China. *These authors contributed equally to this work. Correspondence and requests for materials should be addressed to D.S. (email: dfsun@upc.edu.cn) 
(a)<smiles>O=C(O)c1cc(C(=O)O)cc(-c2c3ccccc3c(-c3cc(C(=O)O)cc(C(=O)O)c3)c3ccccc23)c1</smiles>

(b)

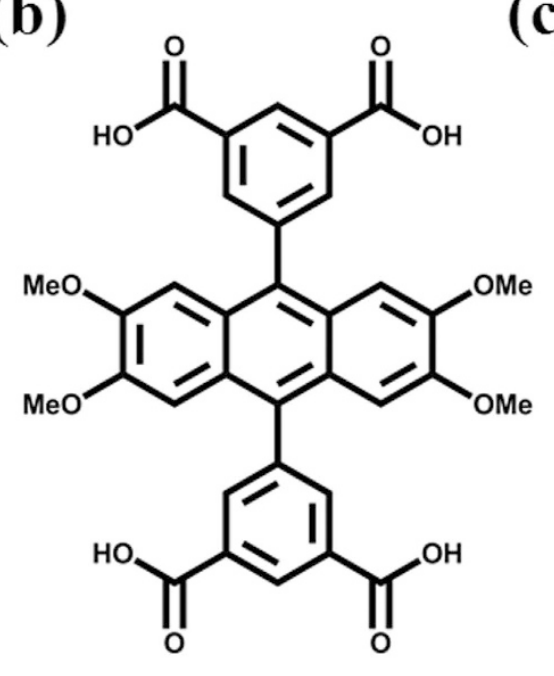

(c)

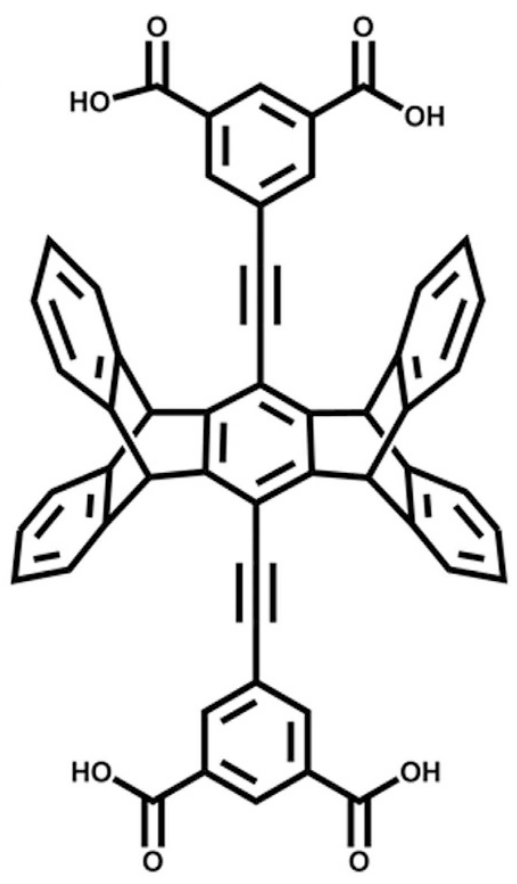

Figure 1. The tetracarboxylate ligands used in our previous works (a,b) and this work (c).

coworkers $^{35}$. However, porous MOFs based on pentiptycene-based ligands with gas uptake and fluorescent sensors remain unexplored to date.

Continuing our previous work by use of rigid tetracarboxylate ligands (Fig. 1a,b) to construct porous MOFs ${ }^{36-}$ ${ }^{40}$, we further extended the central anthracene core to pentiptycene core to synthesize a new pentiptycene-based tetracarboxylate ligand, $\mathrm{H}_{4} \mathbf{L}$ (Fig. 1c). The solvothermal reaction between $\mathrm{H}_{4} \mathbf{L}$ and $\mathrm{Cu}\left(\mathrm{NO}_{3}\right)_{2} \cdot 3 \mathrm{H}_{2} \mathrm{O}$ resulted in the formation of a large amount of green crystals. Single-crystal X-ray diffraction, elemental analysis and TGA measurements reveal that the formula of the complex is $\left[\mathrm{Cu}_{3}(\mathbf{L})_{1.5}\left(\mathrm{H}_{2} \mathrm{O}\right)_{3}\right] \cdot 3 \mathrm{DEF} \cdot 20 \mathrm{H}_{2} \mathrm{O}(\mathbf{U P C}-21)$. UPC-21 exhibits selective adsorption of $\mathrm{CO}_{2}$ and highly efficient detection of NACs. To the best of our knowledge, the sensitivity of UPC-21 on the detection of NACs keeps a record among the reported MOF-based fluorescent sensors.

\section{Results and Discussion}

Crystal structure of UPC-21. Single crystal X-ray diffraction analyses reveal that UPC-21 crystallizes in the monoclinic $C 2 / c$ space group and is a $3 \mathrm{D}$ porous framework based on $\mathrm{Cu}_{2}(\mathrm{COO})_{4}$ paddlewheel SBUs. There are three $\mathrm{Cu}^{2+}$ ions, three halves of $\mathbf{L}^{4-}$ ligands, and three coordinated water molecules in the asymmetric unit. Hence, the paddlewheel SBUs are connected by the backbone of $\mathbf{L}^{4-}$ ligands to generate a 3D porous framework. If the tetracarboxylate ligand of $\mathbf{L}^{4-}$ can be considered as a 4-connected planar linker and the paddlewheel SBU as a square planar node, the present framework is a $\mathrm{NbO}$ network with the short Schläfli vertex notation of the net being $\left\{6^{\wedge} 4.8^{\wedge} 2\right\}$. Indeed, the framework contains spindle-shaped cages and each cage is connected with other eight similar cages. Thus, UPC-21 can also be considered as formed by the infinite connection of the spindle-shaped cages (Fig. 2). The total accessible volume in UPC-21 is 54.2\% using the PLATON/VOID routine ${ }^{41}$, after the removal of the axial coordinated water molecules of the paddlewheel SBU.

Gas sorption properties. In order to confirm the permanent porosities of UPC-21, various gas adsorption isotherms of UPC-21 were measured under various temperature. Before the measurement, the freshly prepared sample of UPC-21 was extracted by soxhlete extraction with acetone for 36 hours, then activated at $80^{\circ} \mathrm{C}$ to generate solvent-free sample of UPC-21. As shown in Fig. 3, desolvated UPC-21 displays a typical Type-I adsorption isotherm with the Brunauer-Emmett-Teller (BET) surface area and Langmuir surface area being 1117.0 and $1253.6 \mathrm{~m}^{2} \mathrm{~g}^{-1}$, respectively. Low-pressure $\mathrm{H}_{2}$ and $\mathrm{CO}_{2}$ uptakes of desolvated sample of UPC-21 were also determined using volumetric gas adsorption measurements, which exhibit the classical reversible Type-I isotherms. The type of adsorption suggests typically microporous having been retained after the removal of guest molecules. The PXRD pattern is consistent with that of the pristine sample, which also indicates that the structure of UPC21 is relatively stable after removing the guest molecules. Under the conditions of $77 \mathrm{~K}$ and 1 bar, the desolvated UPC-21 has a maximum $\mathrm{H}_{2}$ uptake of $154 \mathrm{~cm}^{3} \mathrm{~g}^{-1}$. The $\mathrm{H}_{2}$ isosteric heat of adsorption $\left(Q_{\mathrm{st}}\right)$ for UPC-21 was calculated by fitting the $\mathrm{H}_{2}$ adsorption isotherms at $77 \mathrm{~K}$ and $87 \mathrm{~K}$ to a Virial-type expression. At zero coverage, the $Q_{\mathrm{st}}$ has the estimated value of $7.4 \mathrm{~kJ} \mathrm{~mol}^{-1}$, which is comparable to other MOF- 5 series ${ }^{42,43} \cdot \mathrm{CO}_{2}$ measurement for the desolvated UPC-21 indicates that the maximum $\mathrm{CO}_{2}$ uptake is $86.7 \mathrm{~cm}^{3} \mathrm{~g}^{-1}$ under $273 \mathrm{~K}$ and 1 bar, and the corresponding $Q_{\mathrm{st}}$ of $33.6 \mathrm{~kJ} \mathrm{~mol}^{-1}$ was calculated by fitting the $\mathrm{CO}_{2}$ adsorption isotherms at $273 \mathrm{~K}$ and $295 \mathrm{~K}$ to a Virial-type expression. The $Q_{\mathrm{st}}$ value is much higher than other reported MOF materials ${ }^{44}$, indicating that the framework of UPC-21 possesses high affinity to $\mathrm{CO}_{2}$ molecules. 
a)

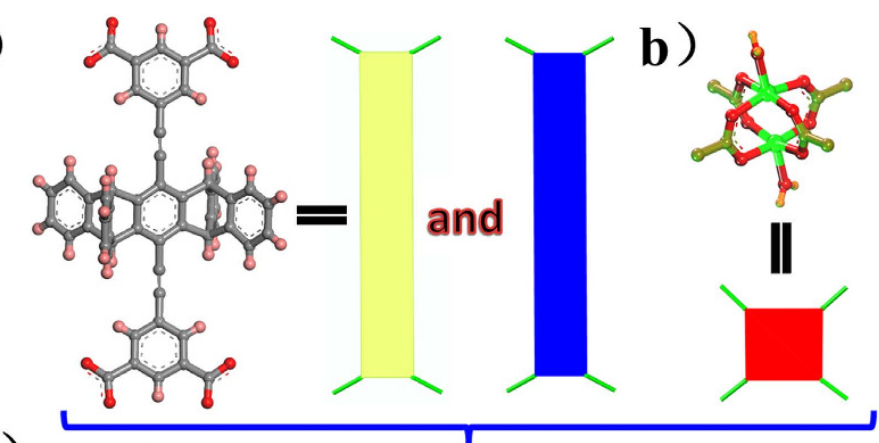

c)
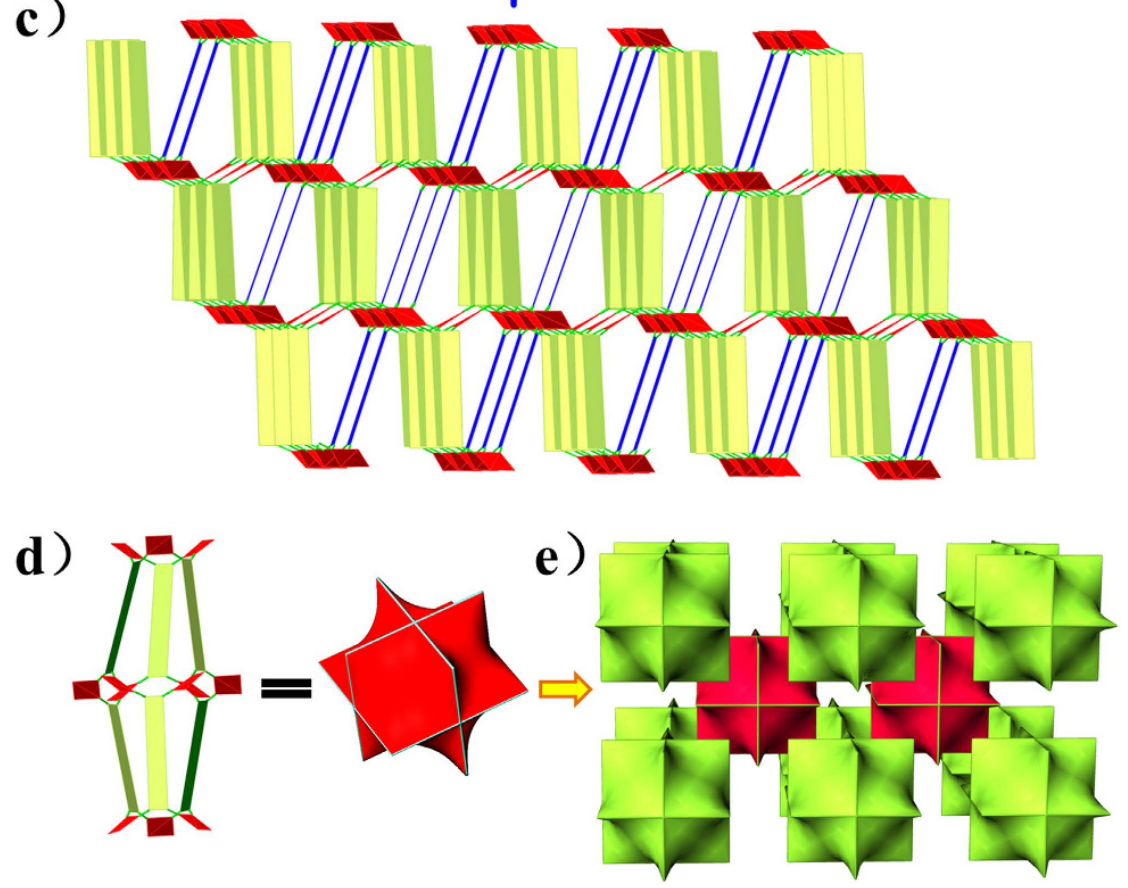

Figure 2. Crystal structure of UPC-21. (a) the square-planar linker of $\mathbf{L}^{4-}$ ligand in UPC-21. (b) The squareplanar node of the paddlewheel SBU. (c) The NbO topological net. (d) Schematic representation of the linkage among the spindle-shaped cages.

Selective adsorption. To further verify the selectivity potential to $\mathrm{CO}_{2}$ over $\mathrm{N}_{2}$ and $\mathrm{CH}_{4}$, the adsorption isotherms of $\mathrm{CO}_{2}, \mathrm{CH}_{4}$, and $\mathrm{N}_{2}$ were measured at $273 \mathrm{~K}$ (Fig. 4) and $295 \mathrm{~K}$ (Figure S5). As shown in Fig. 4, the maximum $\mathrm{CO}_{2}, \mathrm{CH}_{4}$, and $\mathrm{N}_{2}$ uptakes of $86.7,25.4$, and $7.8 \mathrm{~cm}^{3} \mathrm{~g}^{-1}$, respectively, were found at $273 \mathrm{~K}$ and $1 \mathrm{~atm}$. To further evaluate the feasibility of the separations, ideal adsorbed solution theory (IAST) was performed on the basis of the experimentally recorded adsorption isotherms of UPC-21. According to the calculation results over the 10:90 and 50:50 $\mathrm{CO}_{2} / \mathrm{CH}_{4}$ or $\mathrm{CO}_{2} / \mathrm{N}_{2}$ mixed gas, the $\mathrm{CO}_{2} / \mathrm{CH}_{4}$ selectivities are 12.7-7.4 and 10.9-7.5, and the $\mathrm{CO}_{2} / \mathrm{N}_{2}$ selectivities are 70.5-34.3 and 52.2-47.4 for 10:90 and 50:50 mixtures, respectively. These results further indicate that UPC-21 exhibits highly selective adsorption of $\mathrm{CO}_{2}$ over $\mathrm{CH}_{4}$ and $\mathrm{N}_{2}$ at $273 \mathrm{~K}^{45}$.

The separation of $\mathrm{CH}_{4} / \mathrm{C}_{2} \mathrm{H}_{2}$ is also significant in the industrial process. Therefore, the gas separation task becomes increasingly challenge in recent years ${ }^{46-48}$. As shown in Fig. 5(a), the maximum $\mathrm{C}_{2} \mathrm{H}_{2}$ uptake is $72.6 \mathrm{~cm}^{3}$ $\mathrm{g}^{-1}$ at $273 \mathrm{~K}$ and $1 \mathrm{~atm}$, compared to $\mathrm{CH}_{4}$ uptake of $25.4 \mathrm{~cm}^{3} \mathrm{~g}^{-1}$. The selectivity for $\mathrm{C}_{2} \mathrm{H}_{2} / \mathrm{CH}_{4}$ mixture was calculated using the ideal adsorbed solution theory (IAST) as well. Figure 5(b) presents the IAST- derived selectivity of $\mathrm{C}_{2} \mathrm{H}_{2} / \mathrm{CH}_{4}$ for UPC-21. Notably, UPC-21 exhibits substantially high selectivity at very low pressure. $\mathrm{The}_{2} \mathrm{C}_{2} \mathrm{H}_{2} /$ $\mathrm{CH}_{4}$ selectivities are 293.2-91.5 and 128.0-43.7 for 10:90 and 50:50 when the pressure is lower than 0.1 bar.

Fluorescent property and NACs sensing. Fluorescent detection of NACs has received much attention of chemists. In the past decade, a large number of fluorescent MOFs were synthesized and reported. Although these fluorescent MOFs exhibit excellent sensing of NACs, the detection sensitivity needs to be further improved.

Considering the excellent fluorescent property of pentiptycene-based ligand, the photoluminescence of UPC21 in the solid state was studied at room temperature. As shown in Fig. 6a, UPC-21 exhibits a luminescent emission peak at $465 \mathrm{~nm}$, upon excitation at $330 \mathrm{~nm}$. The emission band of UPC-21 can be ascribed to the organic linker, because similar emission at $418 \mathrm{~nm}$ was observed for the free $\mathrm{H}_{4} \mathrm{~L}$ ligand. However, it is noteworthy that the change of luminescence for the UPC-21 with free ligand under the same conditions, which probably can be considered as arising from strong coordination interactions between the ligand and metal ${ }^{49}$. 
(a)

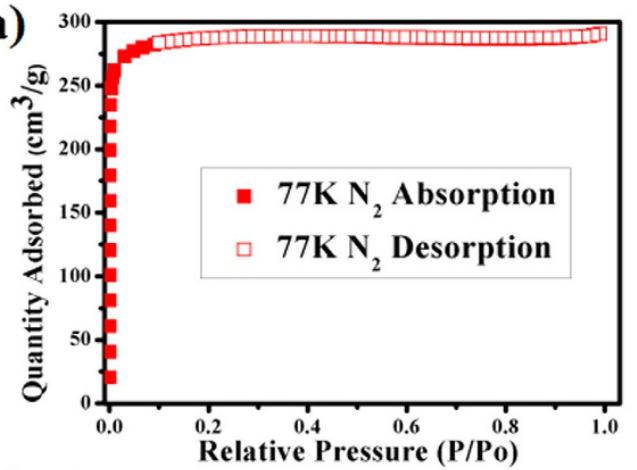

(c)

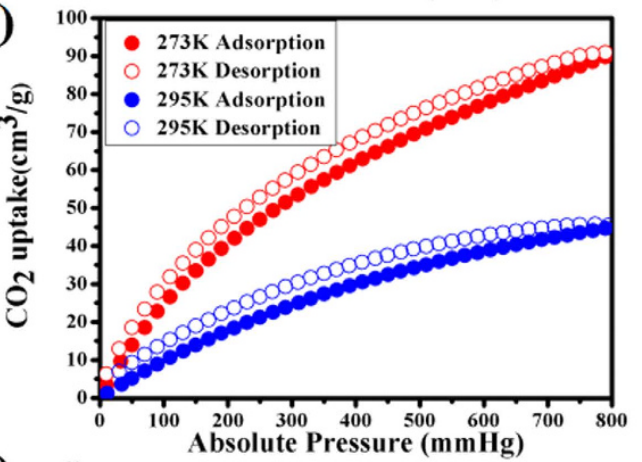

(e)

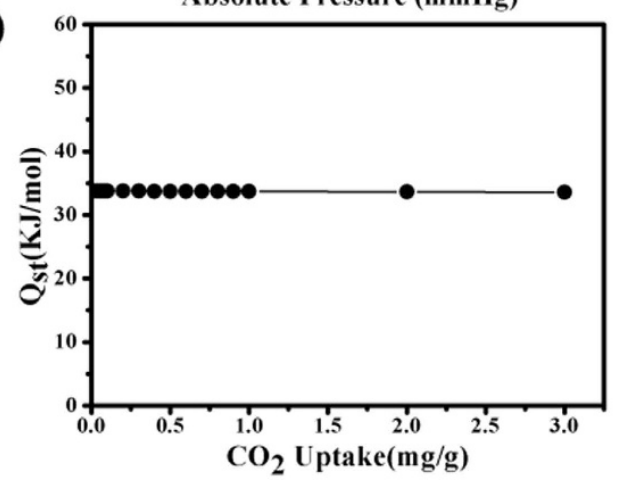

(b)

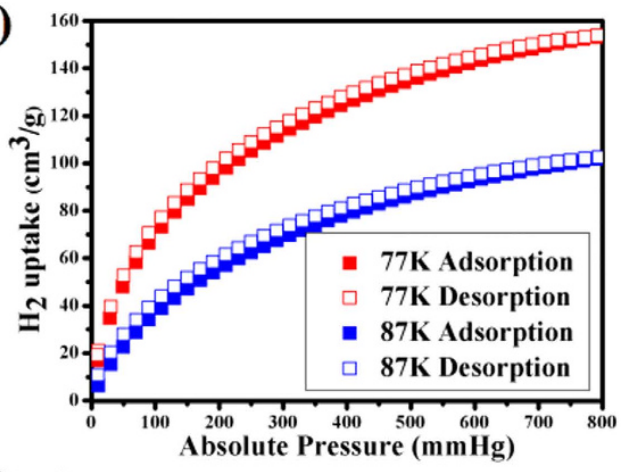

(d)

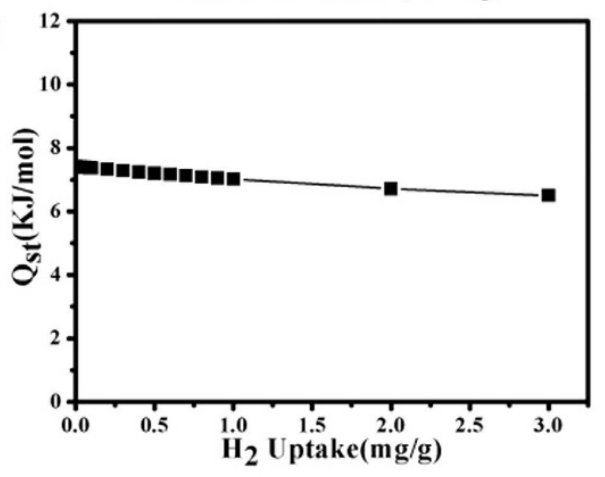

Figure 3. Gas uptakes for UPC-21. (a) The $\mathrm{N}_{2}$ sorption isotherms for UPC-21 at $77 \mathrm{~K}$. (b) The $\mathrm{H}_{2}$ adsorption capacity for UPC-21 at $77 \mathrm{~K}$ and $87 \mathrm{~K}$. (c) The $\mathrm{CO}_{2}$ adsorption capacity for UPC-21 at $273 \mathrm{~K}$ and $295 \mathrm{~K}$. (d) The $Q_{\mathrm{st}}$ of UPC-21 for $\mathrm{H}_{2}$. (e) The $Q_{\mathrm{st}}$ of UPC-21 for $\mathrm{CO}_{2}$

To verify UPC-21 sensing ability to NACs, fluorescent titrations were carried out with the gradual addition of analytes in DMSO to UPC-21 dispersed in DMSO at room temperature. The simplest nitroaromatic compound, nitrobenzene (NB), was first chosen as the analyte. Hence, UPC-21 dispersed in DMSO was titrated with NB in DMSO at room temperature, and the fluorescence change was monitored by PL spectroscopy. Interestingly, the fluorescent intensity increased slightly with the incremental addition of NB, but decreased significantly after further addition of NB at $3 \mathrm{ppm}$, indicating that the introduction of NB produced significant quenching of fluorescence intensity of UPC-21. The fluorescence intensity decreased to $89 \%$ at $10 \mathrm{ppm}$, and no further quenching was observed after $10 \mathrm{ppm}$ (Fig. 7a), indicating that UPC-21 can sense NB molecule with high sensitivity.

Efficient sensing of NB prompted us to investigate the potential of UPC-21 towards sensing other NACs such as 4-nitrophenol (4-NP), 1,4-dinitrobenzene (1,4-DNB), 1,3-dinitrobenzene (1,3-DNB), 4-Nitroaniline(4-NA), and p-nitrotoluene (4-NT). As expected, UPC-21 exhibits efficient sensing of 4-NP with high sensitivity. When only 6 ppm of 4-NP was added to UPC-21 dispersed in DMSO, nearly $98 \%$ of the initial fluorescence intensity was quenched. As contrast, the maximum fluorescence intensity of UPC-21 was decreased by 91, 69, 16 and 15\% upon the addition of 1,4-DNB, 1,3-DNB, 4-NT, and 4-NA at $10 \mathrm{ppm}$, respectively (Fig. 7 and Figure S6). These results indicate that UPC-21 can efficiently sense NB, 4-NP, 1,4-DNB, and 1,3-DNB, in which 4-NP and 1,4-DNB can be detected most effectively. In order to further compare the efficiency of the sensor, the fluorescence quenching efficiency was calculated by use of the Stern-Volmer (SV) equation, $I_{0} / I=1+K_{\mathrm{sv}}[\mathrm{A}]$, where $I_{0}$ is the initial fluorescence intensity before the addition of analyte, $I$ is the fluorescence intensity after adding the analyte as quencher, [A] is the molar concentration of analyte, and $K_{\mathrm{sv}}$ is the quenching constant $\left(\mathrm{M}^{-1}\right)$. In particular, the quenching constant, $K_{\mathrm{sv}}$, can reflect the efficiency of the sensor. Based on the equation, if the $I_{0} / I$ vs [A] plot is linear, then $K_{\mathrm{sv}}$ can be estimated accurately At very low concentrations, the changes of the fluorescence intensity are very slight for 4-NP, NB, 1,3-DNB, and 1,4-DNB. The Stern-Volmer plots are nearly linear at relatively high 
(a)

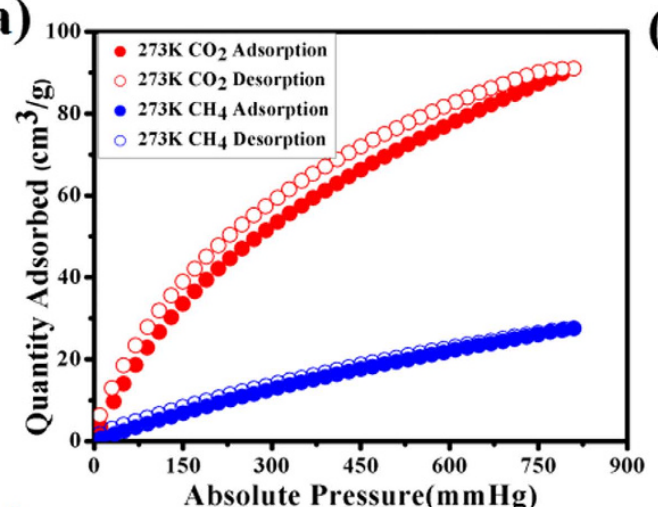

(c)

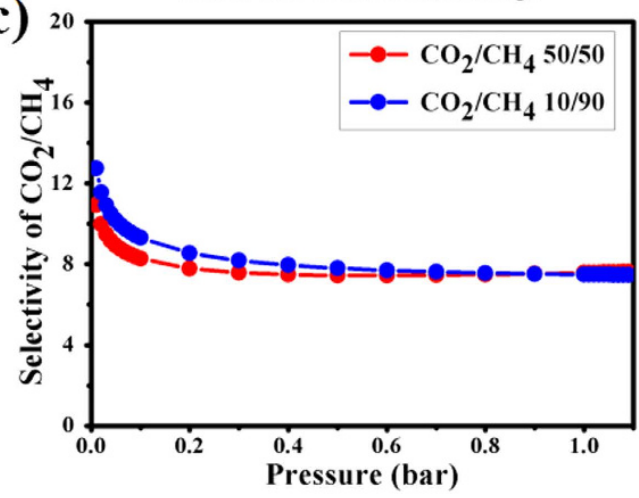

(b)

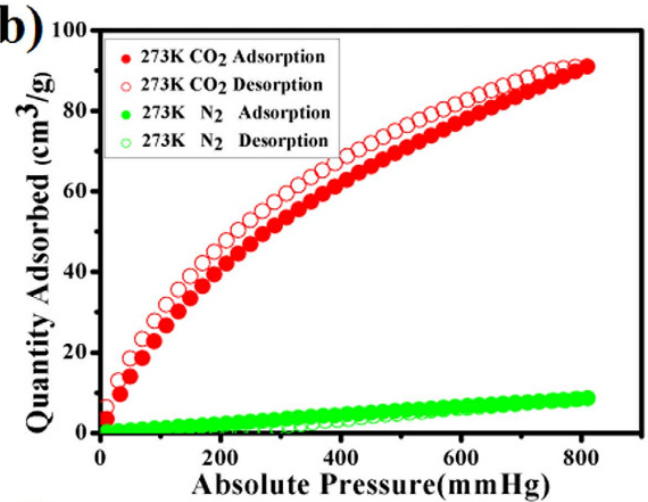

(d)

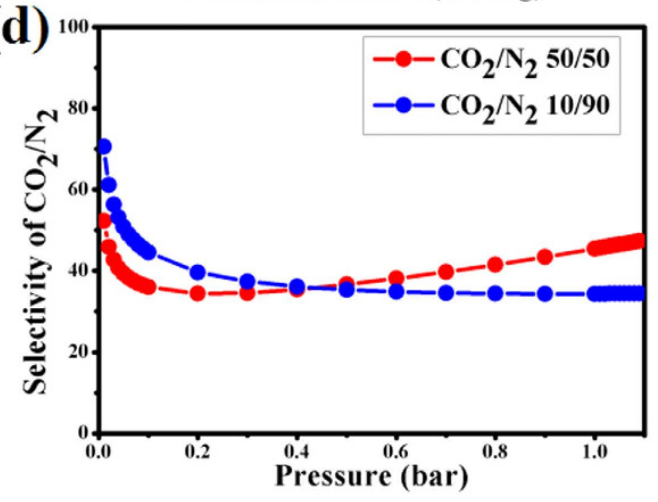

Figure 4. Selective gas adsorption for UPC-21. The $\mathrm{CO}_{2} / \mathrm{CH}_{4}$ (a) and $\mathrm{CO}_{2} / \mathrm{N}_{2}$ (b) sorption isotherms for UPC-21 at $273 \mathrm{~K}$. The $\mathrm{CO}_{2} / \mathrm{CH}_{4}$ (c) and $\mathrm{CO}_{2} / \mathrm{N}_{2}$ (d) selectivities for UPC-21 at $273 \mathrm{~K}$ calculated by the IAST method for two $\mathrm{CO}_{2}$ concentration.

(a)

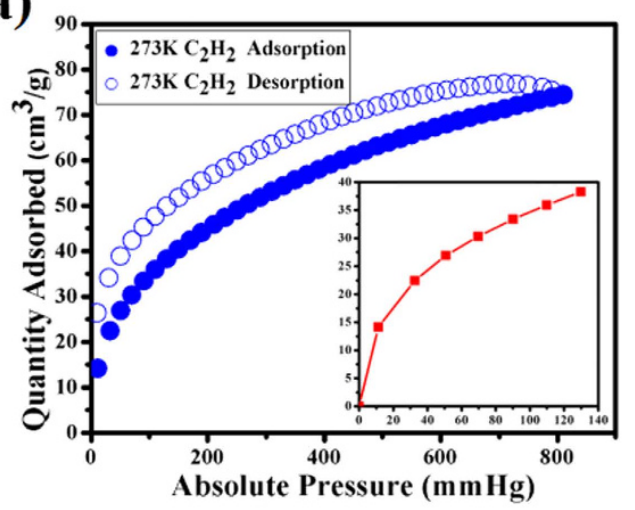

(b)

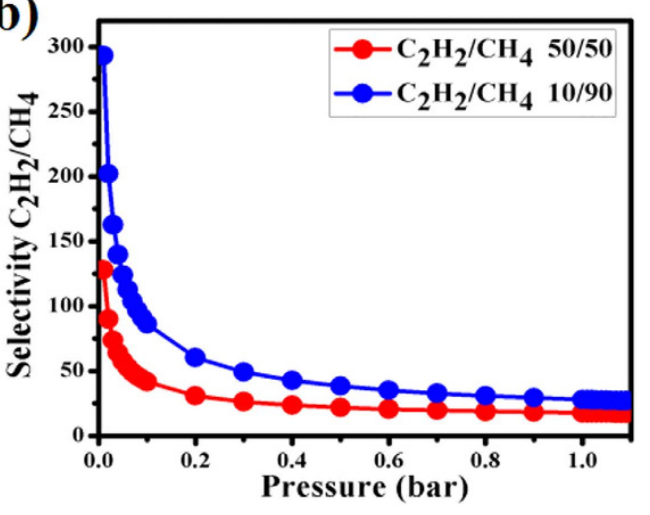

Figure 5. (a) The $\mathrm{C}_{2} \mathrm{H}_{2}$ sorption isotherms for UPC-21 at $273 \mathrm{~K}$. (b) Selectivities for $\mathrm{C}_{2} \mathrm{H}_{2} / \mathrm{CH}_{4}$ at $273 \mathrm{~K}$ calculated by the IAST method.

concentrations for all analytes. The calculated quenching constants, $K_{\mathrm{sv}}$ are $3.097 \times 10^{6}, 1.406 \times 10^{6}, 4.420 \times 10^{5}$, $1.498 \times 10^{5} \mathrm{M}^{-1}$ for 4-NP, 1,4-DNB, NB, 1,3-DNB, respectively, which indicate that the quenching efficiency for the NACs in DMSO is the following order: 4-NP $>1,4-\mathrm{DNB}>\mathrm{NB}>1,3-\mathrm{DNB}$ (Fig. 8). The linear range for NACs detection is 2.5-6 ppm. Recently, several fluorescent MOFs with sensing of 4-NP, 1,4-DNB, NB, and 1,3-DNB were synthesized and reported. As shown in Table 1, UPC-21 exhibits the highest sensitivity among the reported results. Furthermore, the detection limit (D) was calculated based on the equation: $\mathrm{D}=3 \sigma / \mathrm{k},(\sigma:$ standard, $\mathrm{k}$ :slope). The calculated detection limits, $\mathrm{D}$, are about $0.0775,0.0896,0.0949$, and $0.123 \mathrm{ppm}$ for $1,4-\mathrm{DNB}, 4-\mathrm{NP}$, $\mathrm{NB}$, and 1,3-DNB, respectively, which further confirm the high sensitivity of UPC-21 on the fluorescent detection of 4-NP, 1,4-DNB, NB, and 1,3-DNB.

To further explore if UPC-21 can sense other highly explosive NACs with three substituted groups, the fluorescent titrations for 2,4-dinitrotoluene (2,4-DNT) and trinitrophenol (TNP) were carried out. Surprisingly, UPC-21 exhibits highly efficient sensing of TNP but no sensing for 2,4-DNT was observed (Figures S15 and S13). 
(a)

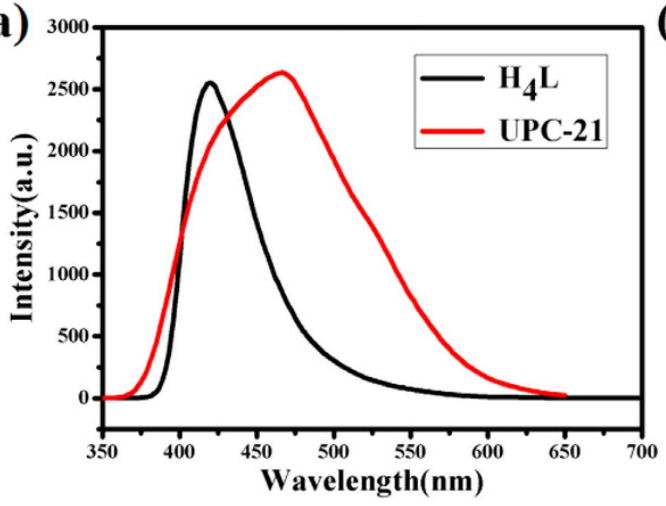

(b)

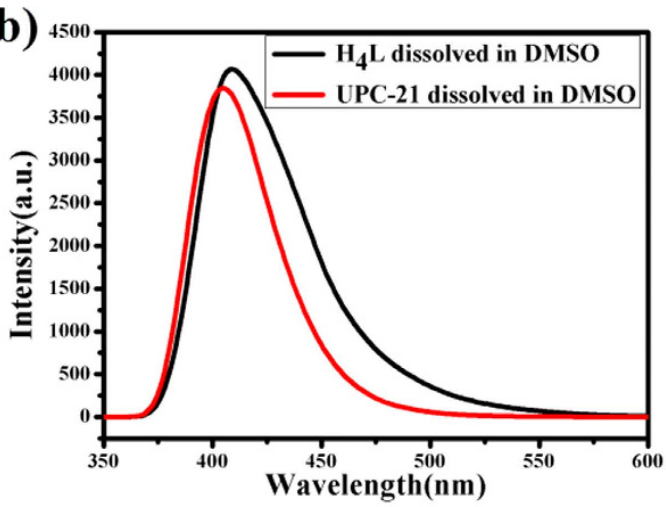

Figure 6. Emission spectra for $\mathrm{H}_{4} \mathrm{~L}$ and UPC-21. (a) The solid state emission spectra for free ligand $\mathrm{H}_{4} \mathrm{~L}$ and UPC-21 at room temperature. (b) The emission spectra for $\mathrm{H}_{4} \mathbf{L}$ dissolved in DMSO and UPC-21 dispersed in DMSO at room temperature.

(a)

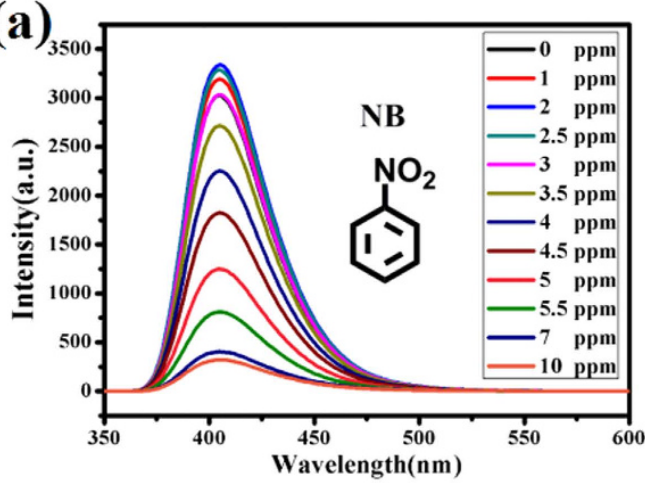

(c)

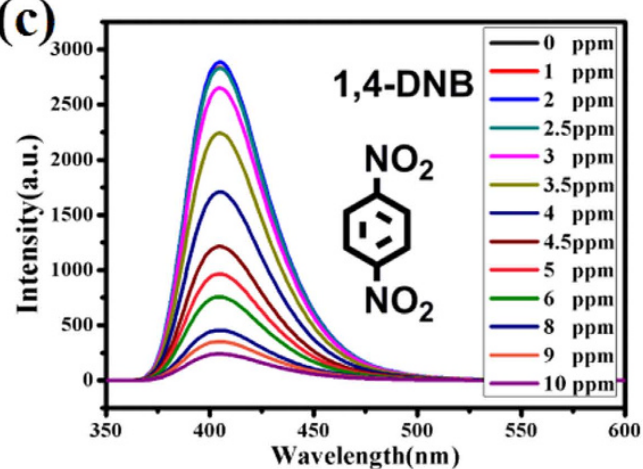

(b)

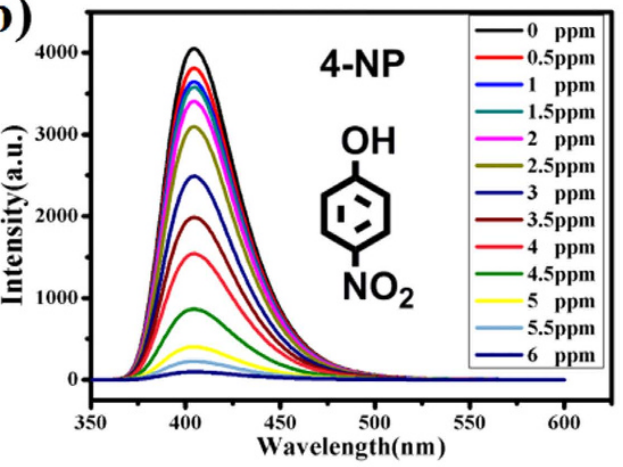

(d)

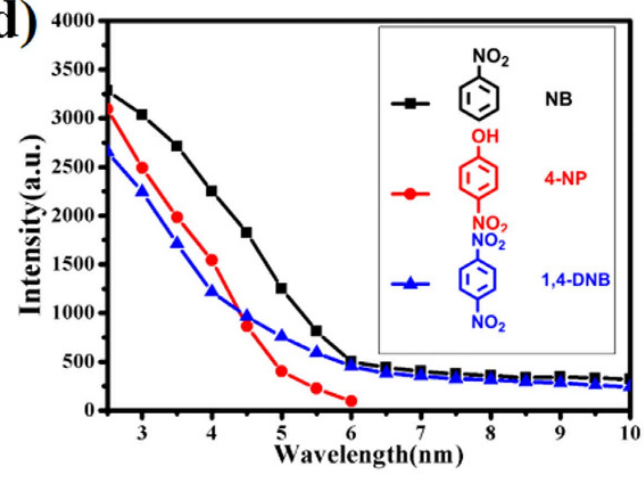

Figure 7. The emission spectra of UPC-21 titrated with NB (a), 4-NP (b), 1,4-DNB (c), and the relationships between emission intensities and concentrations for NB, 4-NP, and 1,4-DNB (d).

The maximum fluorescence intensity of UPC-21 was decreased by $64 \%$ upon the addition of 6 ppm TNP. The calculated $K_{\mathrm{sv}}$ is about $5.209 \times 10^{5} \mathrm{M}^{-1}$ (Figure S16), which is much higher than other reported results ${ }^{50-55}$.

It is known that the fluorescent detection of NACs by MOFs materials should derive from the truth that the fluorescence quenching phenomenon can occur as a result of the electron transfer from the framework of MOFs to the electron-deficient NACs molecules. The high-sensitivity detection of 4-NP and 1,4-DNB by UPC-21 may result from the formation of strong interactions (such as $\pi-\pi$ stacking) between the analytes and the side benzene rings of $\mathbf{L}^{4-}$ ligands after the analytes diffuse into the channels of the framework. In contract, when 1,4-DNB was added gradually to $\mathrm{H}_{4} \mathbf{L}$ dissolved in DMSO, there is no obvious changes for the fluorescence intensity (Figure S18), confirming that the analytes entered into the channels of UPC-21 to interact with the framework. Beside, It should be note that UPC-21 can sense highly explosive for 4-NP, which is possible owing to the presence of the $\mathrm{OH}^{-}$group. With the involving of highly acidic $\mathrm{OH}^{-}$group, strong interaction is occurred via electrostatic interactions, which lead to the quenching effect maintained over a long range. 

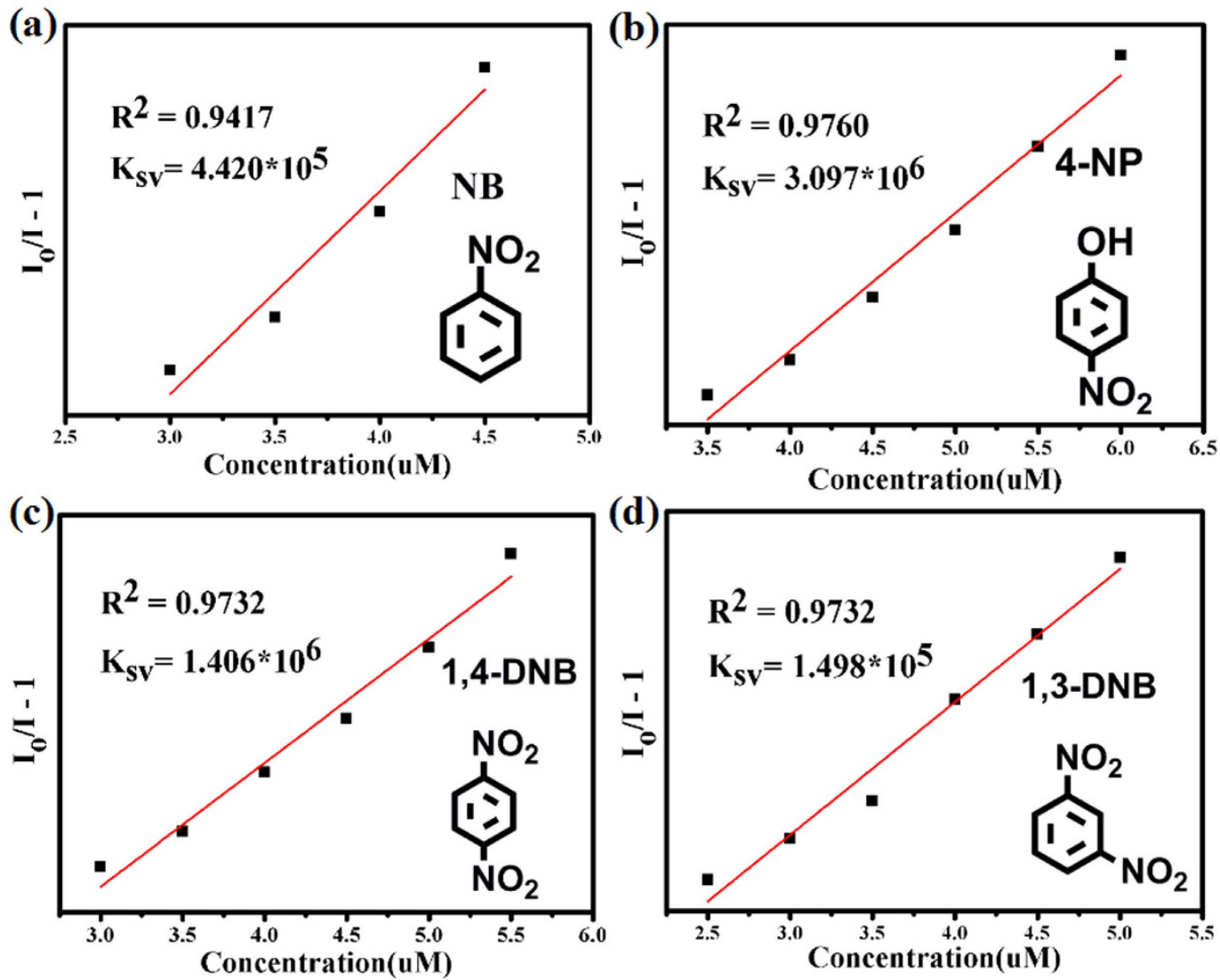

Figure 8. The Stern-Volmer plots for UPC-21 with NB (a), 4-NP (b), 1,4-DNB (c) and 1,3-DNB (d) in the relatively high concentration region. The solid lines represent fit to the concentration-resolved data using the Stern-Volmer equation.

\begin{tabular}{|c|c|c|}
\hline NACs & $K_{\mathrm{sv}} / \mathrm{M}^{-1}$ & Reference \\
\hline 4-NP & $2.2 \times 10^{4}$ & 46 \\
\hline 4-NP & $7.22 \times 10^{4}$ & 56 \\
\hline 4-NP & $3.097 \times 10^{6}$ & UPC-21 \\
\hline NB & $2.2 \times 10^{2}$ & 57 \\
\hline NB & $1.89 \times 10^{3}$ & 58 \\
\hline NB & $2.843 \times 10^{3}$ & 59 \\
\hline NB & $4.13 \times 10^{3}$ & 60 \\
\hline NB & $9.5 \times 10^{2}$ & 61 \\
\hline NB & $1.406 \times 10^{6}$ & UPC-21 \\
\hline 1,4-DNB & $4.526 \times 10^{3}$ & 59 \\
\hline 1,4-DNB & $4.420 \times 10^{5}$ & UPC-21 \\
\hline 1,3-DNB & $5.662 \times 10^{3}$ & 59 \\
\hline 1,3-DNB & $1.5 \times 10^{3}$ & 62 \\
\hline 1,3-DNB & $1.498 \times 10^{5}$ & UPC-21 \\
\hline
\end{tabular}

Table 1. Comparison of sensitivity of selected MOF-based sensors for the detection of NACs.

\section{Conclusions}

In conclusion, a new 3D porous Cu (II) MOF (UPC-21) based on a fluorescent pentiptycene-based ligand was synthesized and characterized. UPC-21 shows selective adsorption of $\mathrm{CO}_{2}$ over $\mathrm{CH}_{4}$ and $\mathrm{N}_{2}$ at $273 \mathrm{~K}$ and $295 \mathrm{~K}$, $\mathrm{C}_{2} \mathrm{H}_{2}$ over $\mathrm{CH}_{4}$ at $273 \mathrm{~K}$, which possesses potential application on gas separation. Significantly, due to the existence of fluorescent ligand of $\mathrm{H}_{4} \mathrm{~L}$ in the compound, UPC-21 exhibits fluorescence detection of 4-NP, 1,4-DNB, $\mathrm{NB}$, and 1,3-DNB with high sensitivities. Furthermore, the calculated quenching constants, $K_{\mathrm{sv}}$, are $3.097 \times 10^{6}$, $1.406 \times 10^{6}, 4.420 \times 10^{5}, 1.498 \times 10^{5} \mathrm{M}^{-1}$ for $4-\mathrm{NP}, 1,4-\mathrm{DNB}, \mathrm{NB}, 1,3-\mathrm{DNB}$, respectively, which keeps a record on the sensitivity of fluorescence detection of NACs. To the best of our knowledge, this work represents the 
first fluorescent $\mathrm{Cu}$ (II) MOF that exhibits high-sensitivity detection of nitroaromatic compounds such as 4-NP, 1,4-DNB. Further study will focus on the synthesis of fluorescent MOFs with other transition metal such as $\mathrm{Zn}^{2+}$ and $\mathrm{Cd}^{2+}$ etc. and $\mathrm{H}_{4} \mathrm{~L}$ ligand, as well as their application on the fluorescence detection of NACs.

\section{Method}

Materials and measurements. All the chemical reagents were obtained from commercial sources and used without further purification. The ligand $\mathrm{H}_{4} \mathrm{~L}$ was synthesized in $60 \%$ yield by a Sonogashira coupling reaction between bis-6,13-(4-acetenyl)pentiptycene and Dimethyl 5-iodoisophthalate followed by hydrolysis with dilute HCl. (Supporting Information, SI). Thermo-gravimetric analysis (TGA) experiments were carried out on a Mettler Toledo TGA instrument with a heating rate $10^{\circ} \mathrm{C} / \mathrm{min}$ at the range of $25-800^{\circ} \mathrm{C}$ under a $\mathrm{N}_{2}$ atmosphere. Elemental analyses $(\mathrm{C}, \mathrm{H}, \mathrm{N})$ were performed on a $\mathrm{CE}$ instruments EA 1110 elemental analyzer. The powder XRD data were obtained on an X-Pert PRO MPD diffractometer with $\mathrm{Cu}-\mathrm{K} \alpha$ radiation. Photoluminescence spectra were recorded with a Hitachi F-7000 Fluorescence Spectrophotometer. Gas-sorption isotherms were carried out on the surface area analyzer ASAP-2020.

Synthesis of UPC-21. Crystal of UPC-21 was synthesized by solvothermal reaction of $\mathrm{Cu}\left(\mathrm{NO}_{3}\right)_{2} \cdot 3 \mathrm{H}_{2} \mathrm{O}$ $(5.0 \mathrm{mg}, 0.021 \mathrm{mmol})$ and $\mathrm{H}_{4} \mathbf{L}(2.0 \mathrm{mg}, 0.0025 \mathrm{mmol})$ in the mixed solvents of $\mathrm{N}, \mathrm{N}$-diethylformamide (DEF) and water. The reaction system was heated to $75^{\circ} \mathrm{C}$ for $1000 \mathrm{~min}$ and cooled to room temperature slowly. Green block crystals of UPC-21 were obtained and dried in air at ambient temperature (yield: $25 \%$, based on Cu). Elemental analysis calc. (\%) for UPC-21: C, 54.58; H, 5.63; N, 1.99. Found: C, 53.13; H, 5.30; N, 2.02 .

Single-crystal X-ray diffraction study. Single crystal structure analysis of UPC-21 was performed on Agilent Xcalibur Eos Gemini diffractometer with Enhance $(\mathrm{Cu}) \mathrm{X}$-ray Source $\mathrm{Cu}-\mathrm{K} \alpha(\lambda=1.54178 \AA)$. An empirical absorption correction was used via the multi-scan method. The structure were solved by direct methods and refined by full-matrix least-squares on F2 using SHELXL-97 ${ }^{1}$. The structure was examined using the Addsym subroutine of PLATON ${ }^{2}$ to assure that no additional symmetry could be applied to the models. Crystal and refinement parameters are listed in Table S1. CCDC No. 1418675 for UPC-21. These data can be obtained free of charge (http://www.ccdc.cam.ac.uk/data_request/cif). Full experimental details and crystallographic analysis are given in the Supplementary Information.

\section{References}

1. Cui, Y. J. et al. A Luminescent Mixed-Lanthanide Metal-Organic Framework Thermometer. J. Am. Chem. Soc. 134. 3979-3982 (2012).

2. Ameloot, R. et al. Interfacial Synthesis of Hollow Metal-Organic Framework Capsules Demonstrating Selective Permeability. Nature 3, 382-387 (2011).

3. Zhou, H. C., Long, J. R. \& Yaghi, O. M. Introduction to Metal-Organic Frameworks. Chem. Rev. 112, 673-674 (2012).

4. Narayan, T. C., Miyakai, T., Seki, S. \& Dinca, M. High Charge Mobility in a Tetrathiafulvalene-Based Microporous Metal-Organic Framework. J. Am. Chem. Soc. 134, 12932-12935 (2012).

5. Yoon, M., Suh, K., Natarajan, S. \& Kim, K. Proton Conduction in Metal-Organic Frameworks and Related Modularly Built Porous Solids. Angew. Chem., Int. Ed. 52, 2688-2700 (2013).

6. Liu, J. et al. Applications of Metal-Organic Frameworks in Heterogeneous Supramolecular Catalysis. Chem. Soc. Rev. 43, 6011-6061 (2014).

7. Cui, Y. J., Yue, Y. F., Qian, G. D. \& Chen, B. L. Luminescent Functional Metal-Organic Frameworks. Chem. Rev. 112, 1126-1162 (2012).

8. Murray, L. J., Dincă, M. \& Long, J. R. Hydrogen Storage in Metal-Organic Frameworks. Chem. Soc. Rev. 38, 1294-1314 (2009).

9. Wei, Z. et al. Rigidifying Fluorescent Linkers by Metal-Organic Framework Formation for Fluorescence Blue Shift and Quantum Yield Enhancement. J. Am. Chem. Soc. 136, 8269-8276 (2014).

10. Fei, H. et al. Reusable Oxidation Catalysis Using Metal-Monocatecholato Species in a Robust Metal-Organic Framework. J. Am. Chem. Soc. 136, 4965-4973 (2014).

11. Sumida, K. et al. Carbon Dioxide Capture in Metal-Organic Frameworks. Chem. Rev. 112, 724-781 (2012).

12. He, Y. B., Zhou, W., Krishna, R. \& Chen, B. L. Microporous Metal-Organic Frameworks for Storage and Separation of Small Hydrocarbons. Chem. Commun. 48, 11813-11831 (2012).

13. Hou, C. et al. Novel (3,4,6)-Connected Metal-Organic Framework with High Stability and Gas-Uptake Capability. Inorg. Chem. 51, 8402-8408 (2012).

14. Salinas, Y. et al. Optical Chemoosensors and Reagents to Detect Explosives. Chem. Soc. Rev. , 41, 1261-1296 (2012).

15. Zhang, C. et al. A Luminescent Cadmium Metal-Organic Framework for Sensing of Nitroaromatic Explosives. Dalton Trans. 44, 230-236 (2015).

16. Liao, F. et al. Photoinduced Electron Transfer of Poly(o-phenylenediamine)-Rhodamine B Copolymer Dots: Application in Ultrasensitive Detection of Nitrite in Vivo. J. Mater. Chem. A 3, 7568-7574 (2015).

17. Wang, G. Y. et al. Two Luminescent Metal-Organic Frameworks for the Sensing of Nitroaromatic Explosives and DNA Strands. J. Mater. Chem. A 2, 2213-2220 (2014).

18. Nagarkar, S. S., Joarder, B., Chaudhari, A. K., Mukherjee, S. \& Ghosh, S. K. Highly Selective Detection of Nitro Explosives by a Luminescent Metal-Organic Framework. Angew. Chem. Int. Ed. 52, 2881-2885 (2013).

19. Tian, D. et al. A Luminescent Metal-Organic Framework Demonstrating Ideal Detection Ability for Nitroaromatic Explosives. J. Mater. Chem. A 2, 1465-1470 (2014).

20. Chen, B. L., Yang, Y., Zapata, F., Lin, G. N., Qian, G. D. \& Lobkovsky, E. B. Luminescent Open Metal Sites within a Metal-Organic Framework for Sensing Small Molecules. Adv. Mater. 19, 1693-1696 (2007).

21. Dang, S., Ma, E., Sun, Z. M. \& Zhang, H. J. A Layer-structured Eu-MOF as a Highly Selective Fluorescent Probe for Fe ${ }^{3+}$ Detection $^{2}$ through a Cation-exchange Approach. J. Mater. Chem. 22, 16920-16926 (2012).

22. Li, B. et al. A Porous Metal-Organic Framework with Dynamic Pyrimidine Groups Exhibiting Record High Methane Storage Working Capacity. J. Am. Chem. Soc. 136, 6207-6210 (2014).

23. Julian Sculley, J. L., Yuan, D. Q. \& Zhou, H. C. The Current Status of Hydrogen Storage in Metal-Organic Frameworks Updated. Energy Environ. Sci. 4, 2721-2735 (2011).

24. Chen, B. L., Ockwig, N. W., Millward, A. R., Contreras, D. S. \& Yaghi, O. M. High $\mathrm{H}_{2}$ Adsorption in a Microporous Metal-Organic Framework with Open Metal Sites. Angew. Chem. Int. Ed. 117, 4823-4827 (2005). 
25. Mahesh, K. R. \& Subramanian, V. Effects of Structural Modifications on the Hydrogen Storage Capacity of MOF-5. Int. J. Hydrogen Energ. 36, 10737-10747 (2011).

26. Niu, D. et al. Syntheses, Structures, and Photoluminescent Properties of 12 New Metal-Organic Frameworks Constructed by a Flexible Dicarboxylate and Various N-Donor Ligands. Cryst. Growth Des. 12, 2397-2410 (2012).

27. Bloch, E. D. et al. Metal Insertion in a Microporous Metal-Organic Framework Lined with 2,2'-Bipyridine. J. Am. Chem. Soc. 132, 14382-14384 (2010).

28. Brown, J. W. et al. Photophysical pore control in an azobenzene-containing metal-organic framework. Chem. Sci. 4, 2858-2864 (2013).

29. Deng, H. X. et al. A Multi-Metal-Cluster MOF with $\mathrm{Cu}_{4} \mathrm{I}_{4}$ and $\mathrm{Cu}_{6} \mathrm{~S}_{6}$ as Functional Groups Exhibiting Dual Emission with both Thermochromic and Near-IR Character. Chem. Sci. 327, 846-850 (2013).

30. Furukawa, H., Cordova, K. E., O’Keeffe, M. \& Yaghi, O. M. The Chemistry and Applications of Metal-Organic Frameworks. Science 341, 1230444 (2013).

31. Wang, R. M. et al. Porous Zirconium Metal-Organic Framework Constructed from 2D $\rightarrow$ 3D Interpenetration Based on a 3,6-Connected kgd Net. Inorg. Chem. 53, 7086-7088 (2014).

32. Crane, A. K., Wong, E. Y. L. \& MacLachlan, M. J. Metal-Organic Frameworks from Novel Flexible Triptycene- and Pentiptycenebased Ligands. CrystEngComm, 15, 9811-9819 (2013).

33. Yang, J. \& Swager, T. M. Fluorescent Porous Polymer Films as TNT Chemosensors: Electronic and Structural Effects. J. Am. Chem. Soc. 120, 11864-11873 (1998).

34. Cordovilla, C. \& Swager, T. M. Strain Release in Organic Photonic Nanoparticles for Protease Sensing. J. Am. Chem. Soc. 134, 6932-6935 (2012).

35. Angela, K. C., Nicholas, G. W. \& Mark, J. M. Metal Organic Frameworks from Extended, Conjugated Pentiptycene-based Ligands. CrystEngComm, 17, 4912-4918 (2015).

36. Liu, F. L. et al. Five MOFs with Different Topologies Based on Anthracene Functionalized Tetracarboxylic Acid: Syntheses, Structures, and Properties. CrystEngComm, 16, 2917-2928 (2014).

37. Zhang, L. L. et al. Crystal Structure Diversities Based on 4,4'-(2,3,6,7- Tetramethoxyanthracene-9,10-diyl)dibenzoic Acid: From 2D Layer to 3D Net Framework. Cryst. Growth Des. 12, 6215-6222 (2012).

38. Ma, S. Q., Simmons, J. M., Sun, D. F., Yuan, D. Q. \& Zhou, H. C. Porous Metal-Organic Frameworks Based on an Anthracene Derivative: Syntheses, Structure Analysis, and Hydrogen Sorption Studies. Inorg. Chem. 48, 5263-5268 (2009).

39. Ma, S. Q. et al. Metal-Organic Framework from an Anthracene Derivative Containing Nanoscopic Cages Exhibiting High Methane Uptake. J. Am. Chem. Soc. 130, 1012-1016 (2008).

40. Wang, X. Q. et al. Synthesis of Two Triarylboron-Functionalized Metal-Organic Frameworks: In Situ Decarboxylic Reaction, Structure, Photoluminescence, and Gas Adsorption Properties. Inorg. Chem. 53, 11206-11212 (2014).

41. Yang, J. et al. Improving the Porosity and Catalytic Capacity of a Zinc Paddlewheel Metal-Organic Framework (MOF) through Metal-Ion Metathesis in a Single-Crystal-to-Single-Crystal Fashion. Inorg. Chem. 53, 10649-10653 (2014).

42. Spek, A. L. The Remodeling Paradox. Implemented as the PLATON Procedure, a Multipurpose Crystallographic Tool, Utrecht University: Utrecht, The Netherlands, (1998).

43. Dixit, M., Maark, T. A. \& Pal, S. Ab Initio and Periodic DFT Investigation of Hydrogen Storage on Light Metal-Decorated MOF-5. Int. J. Hydrogen Energ. 36, 10816-10827 (2011).

44. Srinivasu, K. \& Ghosh, S. K. Tuning the Metal Binding Energy and Hydrogen Storage in Alkali Metal Decorated MOF-5 Through Boron Doping: A Theoretical Investigation. J. Phys. Chem. 115, 16984-16991 (2011).

45. Chen, S. S. et al. Porous Cobalt(II)-Imidazolate Supramolecular Isomeric Frameworks with Selective Gas Sorption Property. Chem. Commum. 47, 4902-4904 (2011).

46. Wang, X. Q. et al. Lanthanide Metal-Organic Frameworks Containing a Novel Flexible Ligand for Luminescence Sensing of Small Organic Molecules and Selective Adsorption. J. Mater. Chem. A 3, 12777-12785 (2015).

47. He, Y. B., Krishna, R. \& Chen, B. L. Metal-Organic Frameworks with Potential for Energy-efficient Adsorptive Separation of Light Hydrocarbons. Energy Environ. Sci. 5, 9107-9120 (2012).

48. Das, M. C. et al. Conjugated Microporous Polymers as Molecular Sensing Devices: Microporous Architecture Enables Rapid Response and Enhances Sensitivity in Fluorescence-On and Fluorescence-Off Sensing. J. Am. Chem. Soc. 134, 8703-8710 (2012).

49. Yang, J. et al. Syntheses, Crystal Structure, and Properties of Four Metal-Organic Complexes Based on 1,4,5,6,7,7- Hexachlorobicyclo [2.2.1] hept-5-ene-2,3-dicarboxylic Acid. Cryst. Growth Des. 15, 4198-4205 (2015).

50. Dalapati, S. et al. An Azine-Linked Covalent Organic Framework. J. Am. Chem. Soc. 135, 17310-17313 (2013).

51. Nagarkar, S. S., Joarder, B., Chaudhari, A. K., Mukherjee, S. \& Ghosh, S. K. Highly Selective Detection of Nitro Explosives by a Luminescent Metal-Organic Framework. Angew. Chem., Int. Ed. 52, 2881-2885 (2013).

52. Khatua, S. et al. Stable Multiresponsive Luminescent MOF for Colorimetric Detection of Small Molecules in Selective and Reversible Manner. Chem. Mater. 27, 5349-5360 (2015).

53. Wang, M. et al. Coordination-Driven Self-Assembly of $\mathrm{M}_{3} \mathrm{~L}_{2}$ Trigonal Cages from Preorganized Metalloligands Incorporating Octahedral Metal Centers and Fluorescent Detection of Nitroaromatics. Inorg. Chem. 50, 1506-1512 (2011).

54. Venkatramaiah, N., Kumar, S. \& Patil, S. Fluoranthene Based Fluorescent Chemosensors for Detection of Explosive Nitroaromatics .Chem. Commun. 48, 5007-5009 (2012).

55. Wu, P. J., Kuo, S. Y., Huang, Y. C., Chen, C. P. \& Chan, Y. H. Polydiacetylene-Enclosed Near-Infrared Fluorescent Semiconducting Polymer Dots for Bioimaging and Sensing. Anal. Chem. 86, 4831-4839 (2014).

56. Bae, Y. S. et al. High Propene/Propane Selectivity in Isostructural Metal-Organic Frameworks with High Densities of Open Metal Sites. Angew. Chem., Int. Ed. 51, 1857-1860 (2012).

57. Kumar, R. et al. Tripodal Fluorescent Sensor for Encapsulation-Based Detection of Picric Acid in Water. Asian J. Org. Chem. 3, 805-813 (2014)

58. Liu, T. H. et al. Photochemical Stabilization of Terthiophene and Its Utilization as a New Sensing Element in the Fabrication of Monolayer-Chemistry-Based Fluorescent Sensing Films. Appl. Mater. Interfaces. 3, 1245-1253 (2011).

59. Ding, L. P. et al. A Single Fluorescent Self-assembled Monolayer Film Sensor with Discriminatory Power. J. Mater. Chem. 22, 11574-11582 (2012).

60. Dinda, D., Gupta, A., Shaw, B. K., Sadhu, S. \& Saha, S. K. Highly Sensitive and Selective Detection of 2,4,6-Trinitrophenol Using Covalent-Organic Polymer Luminescent Probes. Appl. Mater. Interfaces. 6, 10722-10728 (2014).

61. Qian, J. J. et al. Fabrication of Magnetically Separable Fluorescent Terbium-Based MOF Nanospheres for Highly Selective TraceLevel Detection of TNT. Dalton Trans. 43, 3978-3983 (2014).

62. He, H. M. et al. A Porous Metal-Organic Framework Formed by a V-Shaped Ligand and Zn(II) ion with Highly Selective Sensing for Nitroaromatic Explosives. J. Mater. Chem. A 3, 16598-16603 (2015)

\section{Acknowledgements}

This work was supported by the NSFC (Grant No. 21271117, 21571187), NCET-11-0309, the Shandong Natural Science Fund for Distinguished Young Scholars (JQ201003), and the Fundamental Research Funds for the Central Universities (13CX05010A, 14CX02158A). 


\section{Author Contributions}

M.H.Z. and L.L.Z. contributed equally to this work. M.H.Z., L.L.Z. and D.F.S. conceived and designed the research. M.H.Z. synthesized the compounds. Z.Y.X., Q.H.Z. and R.M.W. performed the physical measurements. L.L.Z. and F.N.D. were responsible for solving the crystal structures, analyzing the X-ray structural data and interpreting the results. D.F.S. was responsible for the overall design, direction and supervision of the project. All authors discussed the results and contributed to writing the manuscript.

\section{Additional Information}

Supplementary information accompanies this paper at http://www.nature.com/srep

Competing financial interests: The authors declare no competing financial interests.

How to cite this article: Zhang, M. et al. Pentiptycene-Based Luminescent $\mathrm{Cu}$ (II) MOF Exhibiting Selective Gas Adsorption and Unprecedentedly High-Sensitivity Detection of Nitroaromatic Compounds (NACs). Sci. Rep. 6, 20672; doi: 10.1038/srep20672 (2016).

(c) (i) This work is licensed under a Creative Commons Attribution 4.0 International License. The images or other third party material in this article are included in the article's Creative Commons license, unless indicated otherwise in the credit line; if the material is not included under the Creative Commons license, users will need to obtain permission from the license holder to reproduce the material. To view a copy of this license, visit http://creativecommons.org/licenses/by/4.0/ 